\title{
Community-Based Health Insurance Utilization and Its Associated Factors among Rural Households in Akaki District, Oromia, Ethiopia, 2021
}

\author{
Amenti Teka Geferso $\mathbb{D}^{1}$ and Sisay Begashaw Sharo $\mathbb{D}^{2}$ \\ ${ }^{1}$ Adama General Hospital and Medical College, Department of Public Health (MPH), Adama, Oromia, Ethiopia \\ ${ }^{2}$ Adama Hospital and Medical College, Department of Reproductive Health (MPH), Adama, Oromia, Ethiopia
}

Correspondence should be addressed to Sisay Begashaw Sharo; firo77.sb@gmail.com

Received 12 November 2021; Accepted 26 January 2022; Published 27 February 2022

Academic Editor: Bayu Begashaw Bekele

Copyright (c) 2022 Amenti Teka Geferso and Sisay Begashaw Sharo. This is an open access article distributed under the Creative Commons Attribution License, which permits unrestricted use, distribution, and reproduction in any medium, provided the original work is properly cited.

\begin{abstract}
Background. Community-based health insurance is widely recognized as the most effective way to achieve universal health coverage (UHC) with adequate financial protection against healthcare costs, to promote equal access to high-quality healthcare, increase financial security, and enhance social cohesion and solidarity. Objective. The objective of this study was to determine community-based health insurance utilization and its associated factors among rural households in Akaki District, Oromia special zone surrounding Finfinnee, Oromia, Ethiopia, in May 2021. Methods and Materials. A community based cross-sectional study was conducted on 600 households in May 2021. A multistage sampling technique was used to select households. Data were collected using pretested and standardized questionnaires entered into Epi Info version 7.2.4 and analyzed using SPSS version 26. Bivariate and multivariate logistic regressions were computed to identify the factors associated with community-based health insurance utilization. A $P$ value $<0.05$ with $95 \%$ CI was used as a cut-off point to declare the level of statistical significance. Results. The magnitude of community-based health insurance (CBHI) utilization was 398 (66.3\%) (95\% CI: 0.63, 0.70). In the multivariate logistic regression analysis, the odds of CBHI utilization for males were 2 times higher ( $\mathrm{AOR}=1.629 ; 95 \% \mathrm{CI}: 1.063$, 2.497) compared to female-headed households; household family size $<5$ was 3 times higher ( $\mathrm{AOR}=2.99 ; 95 \% \mathrm{CI}: 1.987,4.139$ ) compared to household family size $>5$; farmer was 4 times higher (AOR $=3.763$; 95\% CI: 1.371, 10.327) compared to other occupational status; household income $<30,000 \mathrm{ETB}$ was 2 times higher (AOR $=2.474 ; 95 \% \mathrm{CI}$ : 1.514, 4.043) compared to the household income of $30000 \mathrm{ETB}$, and all these were factors significantly associated with CBHI utilization. Conclusion. The magnitude of CBHI utilization was low (66.3\%) compared to the HSTP II target (80\%) and other studies. The results of the study showed that age, sex, household family size, household income, and trustworthiness were among the factors significantly associated with community-based health insurance utilization.
\end{abstract}

\section{Introduction}

Community-based health insurance scheme is recognized to be a powerful method to achieve universal health service coverage with sufficient financial protection against healthcare costs. It is one of the solutions proposed by the World Health Organization to improve universal health coverage, but few low-income countries have been able to mount mandated funding solutions for universal health coverage. Evidence shows that, over the past decades, many low-income countries were challenged to sustain healthcare financing and spent on average less than $\$ 23$ per person $[1,2]$.

The overall objective of community-based health insurance coverage is to promote equitable access to sustainable quality healthcare, increase financial protection, and enhance social solidarity. It is obvious that, in most of developing countries, healthcare costs are mostly paid at the time of illness and out of pocket at the time-of-service delivery, which could limit access to health services. 
However, community-based health insurance is one of the types of health insurance and it is essential to provide financial protection by reducing out-of-pocket expenditure and improving the quality of health services $[2,3]$.

Many African countries and other developing countries are limited to providing qualified and affordable health services due to economic problems and their health finance depends on external funding support. The study conducted in Nigeria indicates that only $3.52 \%$ of the entire budget is allocated to enhance health services which are below WHO recommendations which are insufficient to protect the population from out-of-pocket healthcare costs [4].

Ethiopia is one of the developing countries and has developed a health policy to provide healthcare for the population on a scheme of payment according to the ability with special assistance mechanisms for those who cannot afford to pay for their healthcare needs [5].

Thus, different kinds of literature indicate that many factors are contributing to the low CBHI utilization and, as a result, this study was aimed at community-based health insurance utilization and its associated factors among rural households in Akaki District, Oromia, Ethiopia, in 2021.

\section{Methods and Materials}

2.1. Study Area/Setting and Period. The study was conducted in Akaki District which is located in Oromia Special Zone surrounding Finfinne, Oromia Regional State, Ethiopia, from January to May 2021. Akaki District is located to the east, 47 kilometers away from the capital city of Oromia, Finfinnee. Akaki District is bounded by Adea District in East, Sebeta Hawas District in West, Barek District in South, and Sodo Dachi District in North. Dukem is the capital city of the district. According to data from District Health Office, the district has a population of 87,804 people and 18293 households. The district has 28 rural kebeles, four health centers, 28 health posts, and three private primary clinics in terms of health facilities.

2.2. Study Design and Population. A quantitative community-based cross-sectional research design was used in this study. All households in Akaki District were used as the study's source population. All households located in randomly selected kebeles in Akaki District were used as the study population. All household heads who lived for more than 6 months in the randomly selected kebeles were included in the study. Household heads who did not live for six months or who were unable to be interviewed due to illness or other reasons, as well as those who were employed, were not included in the study.

\section{Sample Size Determination and Sampling Technique}

The sample size for the first objective was calculated using a single proportion formula from Akaki District's households. With the assumption of $5 \%$ margin of error and 95\% CI, Z $\alpha$ /
$2=$ critical value $=1.96$, nonresponse rate $=10 \%$, and design effect $=1.5$.

The assumption of $\mathrm{P}$ for this study was based on similar published research that has been conducted in the West Gojjam Zone, Northwest Ethiopia (25). Therefore, the proportion of community-based health insurance utilization was $58 \%$ based on this.

$$
\mathbf{P}(\text { population proportion })=58 \%,
$$

where $\mathbf{n}$ is required sample size and $d$ is margin error between the sample and the population, which is 0.05 .

The formula for single proportion was applied as follows:

$\mathbf{n}=\left(\frac{Z \alpha}{2}\right)^{2} * P(1-P)=\left(\frac{1.96^{2}}{0.05^{2}}\right) * 0.58 *(1-0.58=374) d 2$

Now since the total sample size for the study is 374 , according to the source from the Akaki District Health Office, the total number of households of the district (reference population) is 18283 , which is $>10,000$ population. Design effect (1.5) was used since we used a two-stage sampling technique, and a $10 \%$ response rate was considered.

Sample size with design effect $=374 * 1.5=561$.

Final sample size $(n)=561+561 * 10 \%$ (response rate $=617$. Therefore, the final sample size for the study was 617 households.

\section{Sampling Procedure and Technique}

The study was conducted in Akaki District and the respondents were chosen using a multistage sampling design (two stages) technique to obtain study participants. Firstly, representative kebeles were selected from a total of 28 kebeles available using simple random sampling (mainly by the lottery method). Then, using systematic random sampling, the number of households included in the study was determined proportionally to the total number of households in the sampling frame of the selected kebeles. Since all health posts use Community Health Information System (CHIS), the sampling frame (list of all households) was obtained from the family folder available in each kebele. Finally, respondents were selected from framed lists of households using simple random sampling. To obtain the appropriate study participants, a multistage sampling technique was used. First kebeles were selected from a total of available 28 kebeles in the district using simple random sampling (lottery method). Household heads were selected from kebeles using systematic random sampling from the list of households available in the health post. The number between one and the sampling interval was selected using the lottery method and the next samples were drawn accordingly. Finally, the calculated sample size using a single proportion formula was distributed to selected kebeles to get the final study participants (households) (Figure 1).

The sample for each kebele was calculated using $n_{i}=n * N_{i} / N$, where $n_{i}$ represents sample for each kebele, $N_{i}$ 


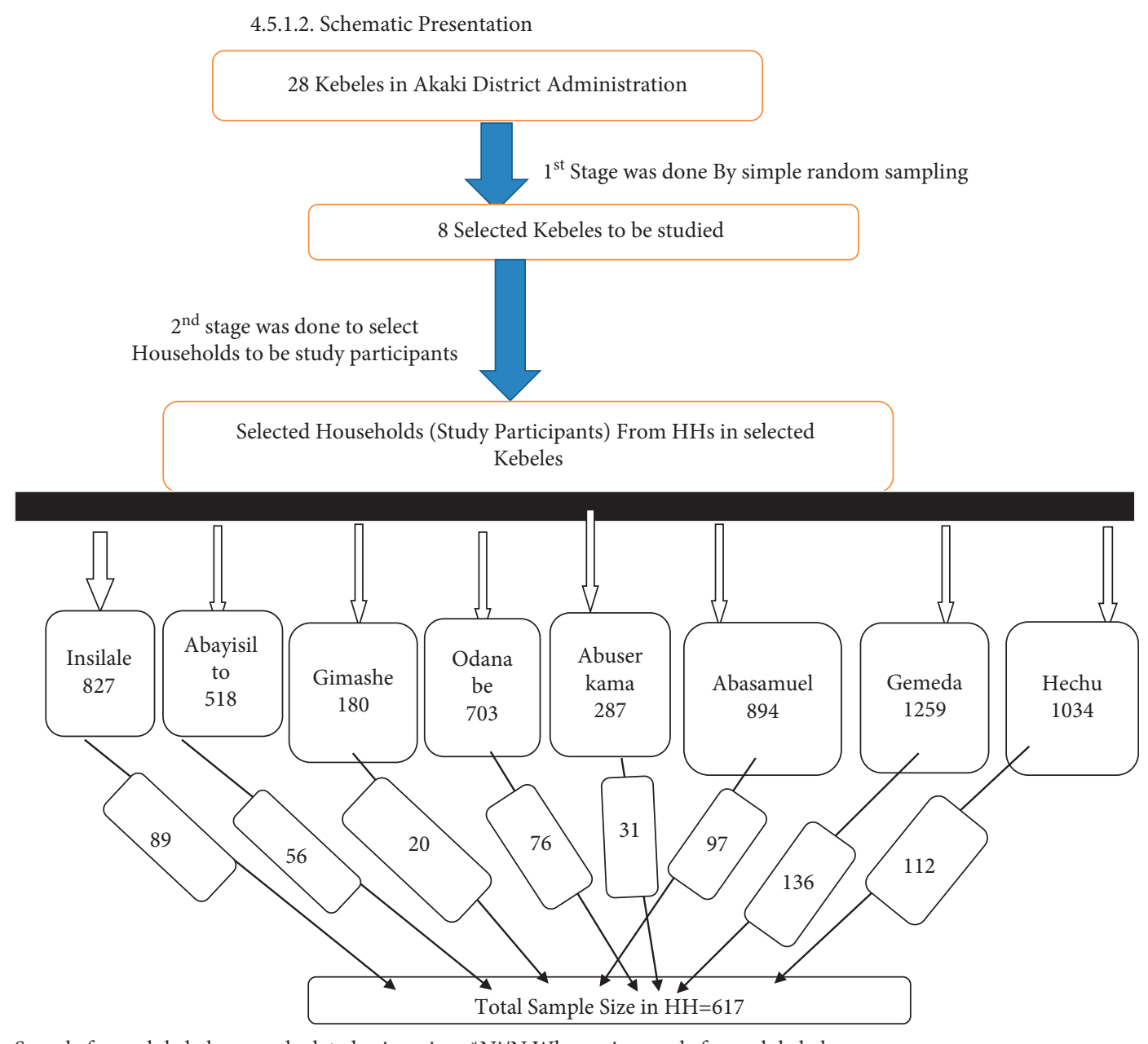

Sample for each kebele was calculated using $\mathrm{ni}=\mathrm{n}^{\star} \mathrm{Ni} / \mathrm{N}$ Where ni=sample for each kebele,

$\mathrm{Ni}=$ each kebele population $(\mathrm{HH}), \mathrm{N}=$ total population for selected kebeles

FIGURE 1: Sampling frame, the sample size calculated for CBHI utilization and its associated factors.

represents each kebele population $(\mathrm{HH})$, and $N$ represents total population for selected kebeles.

\section{Data Collection Tools and Procedures}

A standardized and structured questionnaire was developed based on previously available information and published studies. The questionnaire was first prepared in English and then translated into Afaan Oromoo language for data collection and translated back to the English language for data analysis. It contains variables on sociodemographic and socioeconomic characteristics, utilization, factors affecting community-based health insurance health system, and scheme-related factors.

Data were collected by five qualified data collectors. They were closely monitored under the supervision of the supervisor principal investigator. They were mainly degree and diploma holder health professionals and they were trained by the principal investigator on the objectives of the study and how to fill the questionnaire and maintain privacy and confidentiality during the data collection process.
5.1. Data Quality Control. Data collectors and supervisors were given one-day training on how to collect, manage, and complete data, as well as interviewing techniques, confidentiality, and how to administer the questionnaire and deal with privacy concerns. Data quality was assured by carefully looking at the relevancy of the questionnaire to the objectives of the study. Before the actual data collection, a pretest was conducted on $5 \%$ of the sample $(n=30)$ in nonselected nearby kebeles in the study area. Based on advisor comments and suggestions, the questionnaire's correctness in terms of content structure, imprecise terminology, ambiguous questions, and language has been examined and modified. The data collection process was checked by the principal investigator regularly to ensure that it was complete, accurate, and consistent and that corrective steps were taken.

5.2. Data Processing and Analysis. After the completion of data collection, it was transferred into Epi Info 7 version 2.4. and then exported to SPSS version 26 for cleaning and analysis. Finally, descriptive analyses like frequency, percentage, and mean were used to describe the data. A binary 
logistic regression model was also applied to identify factors associated with community-based health insurance.

Accordingly, those variables with the result of $P$ value $<0.25$ on bivariable logistic regression analysis were considered for multivariable logistic regression analysis. Adjusted odds ratio (AOR) with 95\% confidence interval (CI) was used to measure the strength of association and the variable with $P$ value $\leq 0.05$ was taken as statistically significant for multivariable logistic regression analysis.

\subsection{Operational Definitions}

(1) Premium affordability: affordability in this research was used to assess the perception of household heads on premium affordability: whether it is affordable, somewhat affordable, or not affordable to them.

(2) Community-based health insurance scheme: it is a scheme managed and operated by an organization, other than a government or a private for-profit company, which provides risk pooling to cover all or part of the costs of healthcare services [6].

(3) Community-based health insurance (CBHI): this is a pledge agreement in which the health insurer agrees to cover basic healthcare expenditures in exchange for premium payments to a collective fund that is designed, owned, and managed by members [7].

(4) Community-based health insurance utilization: households that are CBHI members as evidenced by their renewed membership cards, as well as new $\mathrm{CBHI}$ members, are classified as utilizers, whereas those who are not members or have dropped out are classified as nonusers of the CBHI [8].

(5) Enrollment status in CBHI: it is acceptance of CBHI to use and pay a premium for a complete year and possess an updated service card [9].

(6) Health insurance: it is a type of insurance that protects people and families from the risk of medical expenses [9].

(7) Kebele: in Ethiopia, kebele is the lowest administrative unit [10].

(8) Household: a household is a social unit made up of people who live in the same house [10].

(9) Household satisfaction: it is the satisfaction of households with the service given by health professionals in the health facility [10].

(10) Implementation: it is the process of putting a decision or plan into effect execution.

(11) Out-of-pocket payments: individuals' direct payments to healthcare providers at the time of service consumption are referred to as out-of-pocket payments [11].

(12) Revenue: it is the method by which the healthcare system gets financial contributions from various sources [11].
(13) District: it is an Amharic name for a district, which refers to an area of a city, or a collection of kebeles, particularly the one that is considered as a district unit due to a particular characteristic [12].

5.4. Ethical Approval. The study was ethically approved by the Health Research Ethics Review Committee of Adama General Hospital and Medical College by the reference number AGHMC/256/2021 before proceeding to actual data collection and a formal letter was written to Akaki District Health Office. The letter of support was written from Akaki District Health Office to the kebeles administration. The respondents were given details about the intent, potential benefits and side effects, the right to continue or quit the interview, and the study's objectives, and they were given consent to read it for those who could, and the interviewers read it for those who could not. Each respondent was told that their details would be kept private and used only for academic study. The respondents had complete freedom to withdraw from the study at any time or refuse to complete the questionnaires.

\section{Results}

6.1. Sociodemographic and Socioeconomic Characteristics of the Respondents. A total of 600 households participated in the study, with a response rate of $97 \%$, and $493(82.2 \%)$ of the respondents were men. The mean \pm standard deviation of the age of the study, participants was $3.10 \pm 1.035$. Oromo ethnic group was the largest in the study area, accounting for $488(81.3 \%)$ of the study participants. The religious status of the study participants showed that 311 household heads constituting 51.8\% were Orthodox. Most of the respondents, 391 (65.2\%), were unable to write and read because they had not received formal education. 560 (93.3\%) of the study participants were married and 340 (56.7\%) of the respondents had more than five family members with the mean \pm standard deviation of household family size of the respondents being $1.57 \pm 0.496$. The study showed that 481 household heads $(80.2 \%)$ had an annual income of more than thirty thousand Ethiopian Birr (30,000 ETHB). The main source of the household income was from crops production (507 $(85.5 \%)$ ) (Table 1$)$.

6.2. Community-Based Health Insurance Utilization. The overall CBHI utilization in this study was 398 (66.3\%) (95\% CI: $0.63,0.70)$. The majority of the CBHI utilizers decided to enroll in the scheme to finance their healthcare expenses (198 (47.2\%)), while $303(50.5 \%)$ of those who registered have renewed their membership cards. The most common reasons for not utilizing CBHI were lack of interest/willingness to join $(112(55.4 \%))$, benefit package not meeting any healthcare need (34.2\%), and low quality of services (10.4\%) (Figure 2).

6.3. Awareness, Willingness to Join, and Perception on CBHI. Of all respondents, 544 (90.7\%) had heard of the community-based health insurance scheme and were aware of it, 
TABLE 1: Sociodemographic and socioeconomic characteristics of respondents, Akaki District, 2021.

\begin{tabular}{|c|c|c|c|}
\hline Attributes & Categories & Frequency & Percent (\%) \\
\hline \multirow{2}{*}{ Sex } & Male & 493 & 82.2 \\
\hline & Female & 107 & 17.8 \\
\hline \multirow{5}{*}{ Age } & $20-29$ & 55 & 9.2 \\
\hline & $30-39$ & 70 & 11.7 \\
\hline & $40-49$ & 295 & 49.2 \\
\hline & $50-60$ & 121 & 20.2 \\
\hline & $\geq 60$ & 59 & 9.8 \\
\hline \multirow{3}{*}{ Educational Status } & Unable to write and read & 391 & 65.2 \\
\hline & Primary & 169 & 28.2 \\
\hline & Secondary & 40 & 6.7 \\
\hline \multirow{4}{*}{ Marital status } & Married & 560 & 93.3 \\
\hline & Separated & 15 & 2.5 \\
\hline & Widowed & 20 & 3.3 \\
\hline & Divorced & 5 & 0.8 \\
\hline \multirow{2}{*}{ Household members (family size) } & $\leq 5$ & 261 & 43.5 \\
\hline & $>5$ & 339 & 56.5 \\
\hline \multirow{2}{*}{ Annual income } & $<30,000$ & 119 & 19.8 \\
\hline & $\geq 30,000$ & 481 & 80.2 \\
\hline \multirow{2}{*}{ Source of income } & Crops production & 507 & 85.5 \\
\hline & Animal production & 93 & 15.5 \\
\hline
\end{tabular}

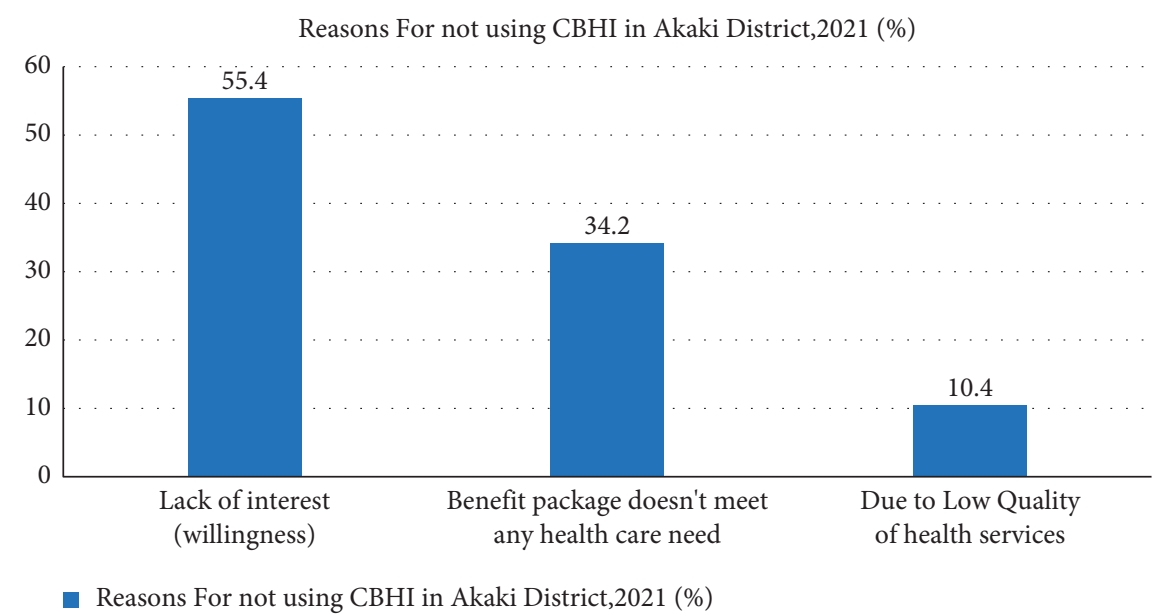

Figure 2: Reasons for not using CBHI in Akaki District, 2021.

and health professionals were the major source of information $(331(60.8 \%)) .398$ (66.3 percent) of the respondents voluntarily enrolled in a community-based health insurance program, while 202 (33.7 percent) were not enrolled for various reasons and $74.8 \%$ of the respondents perceived that $\mathrm{CBHI}$ is necessary to help them get their healthcare needs (Table 2).

6.4. The Scheme Related Factors. All respondents agreed that the community-based health insurance scheme system had not been planned and extended to the kebele level, implying that the CBHI scheme office is still at the district level. The majority of respondents forwarded their ideas on the status of community involvement and frequency of scheme meetings that $376(62.7 \%)$ said the meeting was conducted infrequently.
In terms of trust in the scheme management, only 283 $(47.2 \%)$ had trust in the scheme management system, 336 (56\%) of the respondents agreed that the registration fee is easily affordable, and 336 (56\%) of the respondents agreed that the premium was suitable to pay. Time interval to pay is another issue and the majority of respondents, 273 (45.5\%), agreed that the time interval (payment schedule) is convenient. Of all respondents, 449 (74.8\%) argued that the CBHI scheme is appropriate to assist them in obtaining their healthcare needs (Table 3).

6.5. Health System Related Factors. Of all respondents, 508 $(84.7 \%)$ reported that they had a history of illness in the last six months before data collection, and most of them, 309 (51.5\%), once visited a health facility during illness. All of those who visited health facilities have visited outpatient department 
TABLE 2: Awareness and willingness of respondents to join CBHI, Akaki District, 2021.

\begin{tabular}{lccc}
\hline Attributes & Categories & Frequency & Percent (\%) \\
\hline \multirow{2}{*}{ Awareness of respondents } & Not heard about CBHI & 56 & 9.3 \\
& Ever heard and been aware of CBHI & 544 & 90.7 \\
\hline \multirow{2}{*}{ Voluntarily enrolled into CBHI and utilizing } & Not enrolled in CBHI & 202 & 33.7 \\
& Enrolled in CBHI & 398 & 331 \\
\multirow{2}{*}{ Source of information about CBHI } & Health professionals in health facilities & 93 & 60.8 \\
& CBHI public meeting & 50 & 25 \\
& Neighbors/friends & 4.3 & 4.6 \\
\hline
\end{tabular}

TABLE 3: Scheme related factors associated with CBHI.

\begin{tabular}{|c|c|c|c|}
\hline Attributes & Categories & Frequency & Percent $(\%)$ \\
\hline \multirow{2}{*}{ Ever involvement in CBHI related community meeting } & Not involved in a community meeting & 235 & 39.2 \\
\hline & Ever involved in a community meeting & 365 & 60.8 \\
\hline \multirow{4}{*}{ Status of community involvement and scheme meeting } & Conduct rarely & 376 & 62.7 \\
\hline & Conduct regularly & 15 & 2.5 \\
\hline & Conduct sometimes & 159 & 26.5 \\
\hline & Yet not conducted & 45 & 8.3 \\
\hline \multirow{3}{*}{ Trust in the scheme management system } & Have trust in the scheme management & 283 & 47.2 \\
\hline & Have no trust in the scheme management & 207 & 34.5 \\
\hline & Partially trust in the scheme management & 110 & 18.3 \\
\hline \multirow{3}{*}{$\mathrm{CBHI}$ regular contribution is suitable for your HHs? } & Not suitable & 336 & 56 \\
\hline & Somewhat suitable & 127 & 21.2 \\
\hline & Yes, suitable & 137 & 22.8 \\
\hline \multirow{3}{*}{ The convenience of time interval to pay a premium } & It is somewhat convenient & 151 & 25.2 \\
\hline & No, it is not convenient & 176 & 29.3 \\
\hline & Yes, it is convenient & 273 & 45.5 \\
\hline \multirow{3}{*}{ Affordability of registration fee } & Easily affordable & 336 & 56 \\
\hline & Somewhat affordable & 127 & 21.2 \\
\hline & Unaffordable & 137 & 22.8 \\
\hline
\end{tabular}

(OPD) and received drugs and medical supplies, 496 (82.7\%) got diagnosis and laboratory service, $100(16.7 \%)$ got inpatient service, 135 (22.5\%) obtained delivery service, and 10 (1.7\%) got surgical procedures. Most of those who attended health facilities, 276 (46\%), waited for one to two hours to utilize healthcare services. The public health center was the preferred health facility for $338(56.3 \%)$ respondents due to accessibility to the respondent's residence $(413(68.8 \%))$.

In terms of quality of service, $303(50.5 \%)$ of those who visited health facilities due to illness were satisfied with the healthcare service they got during their visit to the health facility, and 190 (31.7\%) were dissatisfied; 263 (43.8\%) were satisfied with the attitude of health professionals and 230 $(38.3 \%)$ were dissatisfied; $258(43 \%)$ were satisfied with availability of drugs and medical supplies and 235 (39.2\%) were dissatisfied. $233(38.8 \%)$ were satisfied with waiting time from the time of arrival to getting service, while 255 $(42.5 \%)$ were not satisfied. The respondents expressed their opinion that $333(55.5 \%)$ of them were satisfied with the availability of staff and 160 (26.7\%) were dissatisfied with it.

6.6. Factors Associated with Community-Based Health Insurance Utilization. Bivariate logistic regression and multivariable analysis were carried out to determine independent predictors of community-based health insurance utilization. Those candidate variables with $P$ value < 0.25 in bivariate logistic regression were included in multivariable logistic regression and significance was considered in the model if the $P$ value was less than 0.05 .

A result of bivariate logistic regression applied to identify significant independent variables showed that CBHI utilization (CBHI utilization) was significantly associated $(P<0.25)$ with the study participant's age, sex, household family size, occupational status, annual income, awareness, distance from the health facility, history of illness, frequency of visits to the health facility, waiting time to utilize healthcare services during a visit to the health facility, preferred health facility during illness, affordability of premium and registration fee, and trust in the scheme management.

In the multivariate logistic regression analysis, the odds of CBHI utilization for males were 2 times higher ( $\mathrm{AOR}=1.629 ; 95 \% \mathrm{CI}: 1.063,2.497)$ compared to females; the odds of CBHI utilization for household family size of less than or equal to five members were 3 times higher (AOR $=2.99 ; 95 \%$ CI: $1.987,4.139)$ compared to household with greater than five family members; the odds of $\mathrm{CBHI}$ utilization for occupational status of being farmer were 4 times higher $(\mathrm{AOR}=3.763 ; 95 \% \mathrm{CI}: 1.371,10.327)$ compared 
to other occupational statuses; the odds of CBHI utilization for household income $<30,000$ ETHB were 2 times higher (AOR $=2.474 ; 95 \% \mathrm{CI}: 1.514,4.043)$ compared to household income $\geq 30,000$; the odds of awareness about CBHI utilization were about $62 \%(\mathrm{AOR}=0.38$; 95\% CI: $0.015,0.096)$ less compared to nonaware households; the odds of $\mathrm{CBHI}$ utilization for frequency of those who once visited health facility were about 5 times higher $(\mathrm{AOR}=5.183$; 95\% CI: $2.095,12.821)$ compared to frequency of those who made two visits to health facility (AOR $=5.453$; 95\% CI: 2.143 , 13.879) which was 5 times higher compared to that of those who visited health facilities three times; the odds of $\mathrm{CBHI}$ utilization for distance from health facility of $2-5 \mathrm{~km}$ were about 2 times (AOR = 1.909; 95\% CI: 1.300, 2.803) those for distance from health facility $\geq 5 \mathrm{~km}$; the odds of CBHI utilization for waiting time to utilize healthcare service of less than one hour were about 2 times higher $(\mathrm{AOR}=2.011 ; 95 \%$ CI: $1.33,3.034)$ compared to those of their counterparts; the odds of CBHI utilization for public health center preferred during illness were about 3 times higher $(\mathrm{AOR}=3.36 ; 95 \%$ CI: $2.010,5.616)$ and the odds of CBHI utilization for private health facility were $64 \%$ less $(\mathrm{AOR}=0.365$; 95\% CI: 0.190 , $0.699)$ compared to those of preferred public and private hospital; the odds of CBHI utilization for households satisfied with the attitude of healthcare professionals were about $90 \%$ less (AOR $=0.153$; 95\% CI: 0.097, 0.243) compared to those of households that were dissatisfied; the odds of CBHI utilization for households that were satisfied with healthcare services were $90 \%$ less $(\mathrm{AOR}=0.065$; 95\% CI: $0.040,0.108)$ compared to those of households that were dissatisfied with healthcare services; the odds of CBHI utilization for both affordability of premium and registration fee being easily affordable and affordable were about 3 times higher $(\mathrm{AOR}=2.862 ; 95 \% \mathrm{CI}: 1.862,4.399)$ compared to perceived unaffordability; the odds of CBHI utilization for trust in the CBHI scheme management were about $60 \%$ less $(\mathrm{AOR}=0.432 ; 95 \% \mathrm{CI}: 0.285,0.654)$; and the odds of $\mathrm{CBHI}$ utilization for those who trust in the CBHI scheme management were about $70 \%$ less $(\mathrm{AOR}=0.255$; 95\% CI: 0.154 , 0.422 ) compared to those who do not trust in the scheme management (Table 4).

\section{Discussion}

This study found that the magnitude of CBHI utilization among Akaki District households was 66.3\%, which was lower than the findings of a study conducted in Debub Bench District (67\%) and higher than the findings of a study conducted in the South Achefere district (50.5\%), Fogera (38\%), and West Gojjam (58\%) [12-15]. The disparity could have resulted from the level of involvement of influential community members (community leaders, religious leaders, elders, and health development team leaders) in sensitization and awareness-raising activities, differences in awareness, willingness to participate, sociocultural factors, and economic factors, as well as a lack of managerial commitment at the lower levels.

The study showed that $90.7 \%$ of the study participants were aware of and knew community-based health insurance, a percentage lower than that in a study done in Bahir Dar, Northwestern Ethiopia (93.8 percent) and higher than the one of a study conducted in Jimma Zone (31\%). Health professionals have been identified as the primary source of information on CBHI. The disparity could have resulted due to study time difference and the initiation of the $\mathrm{CBHI}$ scheme in the study areas $[16,17]$.

In this study, one of the parameters linked to CBHI usage has been discovered to be age. As a result, the odds of $\mathrm{CBHI}$ utilization among household heads aged 20-29, 30-49, and $50-60$ years were $79 \%, 90 \%$, and $60 \%$ less compared to those of household heads aged 60 years and older. This finding did not agree with the findings of another study conducted in the Jimma Zone, which found that older age household heads (60 and above) were 3.5 times more willing to join the scheme than younger age groups, but it did agree with the findings of studies conducted in Gidda Ayana and Thehuldere. This could be because people of these ages were more likely to attend community meetings and because of time differences and socioeconomic factors $[8,17,18]$.

The study showed that the sex of the respondents was significantly associated with CBHI utilization and the odds of CBHI utilization among males were about 2 times higher compared to female household heads; this finding was contrary to a study conducted in the West Gojjam Zone, where female household heads were 2.7 times more willing to utilize the scheme compared to male household heads, and to a study conducted in Ghana and Mali and systematic review of factors that affect the uptake of $\mathrm{CBH}$ in low- and middleincome countries. This might be due to male households' active participation in community meetings, accessibility to information than females in rural settings [19, 20].

According to this study, family size of households was significantly associated with CBHI utilization. Households with less than or equal to five family members were about 3 times higher linked to CBHI utilization than those with more than five family sizes. This finding was contrary to a study conducted in Fogera District, Northwest Ethiopia, Bugna District, Northeast Ethiopia, and Sabata Hawas, where the household size $>5$ members was willing to pay and utilize CBHI. The difference might be due to sociodemographic factors, the time difference in studies, the difference in willingness to join the scheme among households [21-23].

In terms of annual income, the odds of CBHI utilization among study participants of those who had annual income $<30,000$ ETB were about two times higher compared to those whose annual income was more than 30,000 ETB. This shows that community-based health insurance protects households' financial risks and increases their reliance on CBHI for individuals with lower annual incomes. In other studies, it was discovered that household income had a strong relationship with $\mathrm{CBHI}$ enrollment [10, 19, 24-26].

In this study, the occupational status of the households showed a significant association with CBHI utilization that the odds of CBHI utilization among a farmer was about four times higher compared to another occupational status. This study was in concordance with the findings in Fogera District, Gida Ayana, and Northwest Ethiopia, where farmer 
TABLE 4: Multivariate analysis of factors associated with CBHI utilization among rural households in Akaki District, 2021.

\begin{tabular}{|c|c|c|c|c|c|}
\hline \multirow{2}{*}{ Variables/characteristics } & \multirow{2}{*}{ Categories } & \multicolumn{2}{|c|}{ CBHI utilization } & \multirow{2}{*}{ COR $(95 \% \mathrm{CI})$} & \multirow{2}{*}{$\operatorname{AOR}(95 \% \mathrm{CI})$} \\
\hline & & No $(0)$ & Yes (1) & & \\
\hline \multirow[t]{2}{*}{ Sex } & Male & $\begin{array}{c}156 \\
(31.6 \%)\end{array}$ & $\begin{array}{c}337 \\
(68.4 \%)\end{array}$ & $\begin{array}{c}1.629(1.063 \\
2.497)\end{array}$ & $\begin{array}{l}1.629(1.063 \\
2.497)\end{array}$ \\
\hline & Female & $46(43 \%)$ & $61(57 \%)$ & Ref & \\
\hline \multirow{2}{*}{ Household family size } & $\leq 5$ & $\begin{array}{c}182 \\
(35.6 \%)\end{array}$ & $\begin{array}{c}329 \\
(64.4 \%)\end{array}$ & $\begin{array}{c}2.968(1.987, \\
4.139)\end{array}$ & $\begin{array}{c}2.968(1.987, \\
4.139)\end{array}$ \\
\hline & $>5$ & $\begin{array}{c}20 \\
(22.5 \%)\end{array}$ & $\begin{array}{c}69 \\
(77.5 \%) \\
\end{array}$ & & \\
\hline \multirow{2}{*}{ Occupational status of respondents } & Farmer & $\begin{array}{c}191 \\
(32.8 \%)\end{array}$ & $\begin{array}{c}393 \\
(67.2 \%)\end{array}$ & $\begin{array}{l}3.763(1.371 \\
10.327)\end{array}$ & $\begin{array}{l}3.763(1.371 \\
10.327)\end{array}$ \\
\hline & Merchant & $\begin{array}{c}11 \\
(64.7 \%)\end{array}$ & $6(35.3 \%)$ & & \\
\hline \multirow{2}{*}{ Annual income of respondents } & $<30,000$ & $\begin{array}{c}23 \\
(19.3 \%)\end{array}$ & $\begin{array}{c}96 \\
(80.7 \%)\end{array}$ & $\begin{array}{l}0.474(1.514 \\
\quad 4.043)\end{array}$ & $\begin{array}{l}2.474(1.514 \\
4.043)\end{array}$ \\
\hline & $\geq 30,000$ & $\begin{array}{c}179 \\
(37.2 \%) \\
\end{array}$ & $\begin{array}{c}302 \\
(62.8 \%) \\
\end{array}$ & Ref & \\
\hline \multirow[b]{2}{*}{ Awareness about $\mathrm{CBHI}$} & No & $51(91.1 \%)$ & $5(8.9 \%)$ & Ref & \\
\hline & Yes & $\begin{array}{c}151 \\
(27.8 \%)\end{array}$ & $\begin{array}{c}393 \\
(72.2 \%)\end{array}$ & $\begin{array}{c}0.38(0.015 \\
0.096)\end{array}$ & $\begin{array}{l}0.38(0.015 \\
0.096)\end{array}$ \\
\hline \multirow{3}{*}{$\begin{array}{l}\text { Frequency of visit to health facility during illness to use health } \\
\text { service in previous six months }\end{array}$} & Once & $\begin{array}{c}78 \\
(25.2 \%)\end{array}$ & $\begin{array}{c}231 \\
(74.8 \%)\end{array}$ & $\begin{array}{l}5.183(2.095 \\
12.821)\end{array}$ & $\begin{array}{l}5.183(2.095 \\
12.821)\end{array}$ \\
\hline & Twice & $\begin{array}{c}43 \\
(24.3 \%)\end{array}$ & $\begin{array}{c}134 \\
(75.7 \%)\end{array}$ & $\begin{array}{c}5.453(2.143 \\
13.879)\end{array}$ & $\begin{array}{c}5.453(2.143 \\
13.879)\end{array}$ \\
\hline & Three times & $\begin{array}{c}14 \\
(63.6 \%) \\
\end{array}$ & $8(36.4 \%)$ & Ref & \\
\hline \multirow{3}{*}{ Distance from health facility } & $\leq 2$ & $\begin{array}{c}35 \\
(31.8 \%)\end{array}$ & $\begin{array}{c}75 \\
(68.2 \%)\end{array}$ & Ref & \\
\hline & $2-5 \mathrm{~km}$ & $\begin{array}{c}60 \\
(26.4 \%)\end{array}$ & $\begin{array}{c}167 \\
(73.6 \%)\end{array}$ & $\begin{array}{c}1.909(1.300 \\
2.803)\end{array}$ & $\begin{array}{c}1.909(1.300 \\
2.803)\end{array}$ \\
\hline & $\geq 5$ & $\begin{array}{c}107 \\
(40.7 \%) \\
\end{array}$ & $\begin{array}{c}156 \\
(59.3 \%) \\
\end{array}$ & Ref & \\
\hline \multirow{2}{*}{ Waiting time to utilize health service } & $\begin{array}{c}\text { Less than one } \\
\text { Hour }\end{array}$ & $\begin{array}{c}45 \\
(19.4 \%)\end{array}$ & $\begin{array}{c}187 \\
(80.6 \%)\end{array}$ & $\begin{array}{l}2.011(1.33 \\
3.034)\end{array}$ & $\begin{array}{l}2.011(1.33, \\
3.034)\end{array}$ \\
\hline & 1 to 2 hours & $\begin{array}{c}90 \\
(32.6 \%)\end{array}$ & $\begin{array}{c}186 \\
(67.4 \%)\end{array}$ & Ref & \\
\hline \multirow{2}{*}{ Satisfaction with the attitude of health professionals } & No & $\begin{array}{c}105 \\
(45.7 \%)\end{array}$ & $\begin{array}{c}125 \\
(54.3 \%)\end{array}$ & Ref & \\
\hline & Yes & $\begin{array}{c}30 \\
(11.4 \%) \\
\end{array}$ & $\begin{array}{c}233 \\
(88.6 \%) \\
\end{array}$ & $\begin{array}{c}0.153(0.97 \\
0.243)\end{array}$ & $\begin{array}{c}0.153(0.097 \\
0.243)\end{array}$ \\
\hline \multirow{2}{*}{$\begin{array}{l}\text { Satisfaction with healthcare service you received during a visit } \\
\text { to HF }\end{array}$} & No & $\begin{array}{c}110 \\
(57.9 \%)\end{array}$ & $\begin{array}{c}80 \\
(42.1 \%)\end{array}$ & Ref & \\
\hline & Yes & $25(8.3 \%)$ & $\begin{array}{c}278 \\
(91.7 \%) \\
\end{array}$ & $\begin{array}{l}0.065(0.040 \\
0.108)\end{array}$ & $\begin{array}{l}0.065(0.040 \\
0.108)\end{array}$ \\
\hline \multirow{3}{*}{ Affordability of premium (regular contribution) } & Yes, suitable & $\begin{array}{c}35 \\
(21.6 \%)\end{array}$ & $\begin{array}{c}127 \\
(78.4 \%)\end{array}$ & $\begin{array}{l}2.862(1.862 \\
4.339)\end{array}$ & $\begin{array}{l}2.862(1.862 \\
4.399)\end{array}$ \\
\hline & $\begin{array}{l}\text { Somewhat } \\
\text { suitable }\end{array}$ & $\begin{array}{c}14 \\
(15.4 \%)\end{array}$ & $\begin{array}{c}77 \\
(84.6 \%)\end{array}$ & $\begin{array}{c}4.33(2.362 \\
7.964)\end{array}$ & $\begin{array}{c}4.338(2.362 \\
7.964)\end{array}$ \\
\hline & Not suitable & $\begin{array}{c}153 \\
(44.1 \%) \\
\end{array}$ & $\begin{array}{c}194 \\
(55.9 \%) \\
\end{array}$ & Ref & \\
\hline \multirow{3}{*}{ Trust in the scheme management } & Yes & $\begin{array}{c}105 \\
(37.1 \%)\end{array}$ & $\begin{array}{c}178 \\
(62.9 \%)\end{array}$ & $\begin{array}{l}0.432(0.285 \\
0.654)\end{array}$ & $\begin{array}{l}0.432(0.285 \\
0.654)\end{array}$ \\
\hline & Somewhat & $55(50 \%)$ & $55(50 \%)$ & $\begin{array}{l}0.255(0.154 \\
0.422)\end{array}$ & $\begin{array}{l}0.255(0.154 \\
0.422)\end{array}$ \\
\hline & No & $\begin{array}{c}42 \\
(20.3 \%)\end{array}$ & $\begin{array}{c}165 \\
(79.7 \%)\end{array}$ & Ref & \\
\hline
\end{tabular}


household heads were willing to pay more than others. This might be due to the harvesting season that might be suitable for the farmer to pay the premium and this assured that $\mathrm{CBHI}$ is designed to protect farmers from unexpected healthcare costs $[8,12,27]$.

The odds of CBHI utilization among households who had awareness were $62 \%$ less compared to nonaware households. This study was inconsistent with the findings in West Gojjam where households with good awareness were 3.77 times more willing to join the scheme. The difference might be in the efforts of concerned bodies to create awareness, scheme launch time in the area of the study, and satisfaction with healthcare service quality. This study was also consistent with other studies done in Ethiopia and Nigeria [19, 20, 28-30].

Several studies have shown that CBHI utilization increases the number of visits to health facilities and, similarly, this study showed that the odds of CBHI utilization were about five times higher among study participants who visited health facilities once and those who visited twice compared to those who visited three times and more. This study was in line with the pilot study on the CBHI scheme on healthcare utilization which indicated a $45 \%-64 \%$ increase in the frequency of visits to public facilities and a study conducted in Bangladesh $[30,32]$. This increase could be attributed to community-based health insurance's lowering of healthcare expenses, as well as satisfaction with the healthcare provided and good features of healthcare facilities.

Distance from health facilities was a factor that was associated with community-based health insurance utilization. This study showed that the odds of CBHI utilization among those households $2-5 \mathrm{~km}$ away from health facilities were about two times higher to utilize health services at health facilities compared to households more than five kilometers away from health facilities. This was consistent with other systematic review and meta-analysis studies that reported that $25 \%$ of the unenrolled could not join the scheme due to lack of health facilities near their residences. This result might be proved by the fact that since the distance from the health facility determines health-seeking behavior, the long distance from the community to the health facility was a barrier or facilitator to enrollment and high transport cost was a reason for low enrollment [20, 33].

Another health system-related factor associated with CBHI utilization was waiting time to utilize health services. Waiting time to see medical professionals substantially influences enrollment. This study showed that the odds of CBHI utilization among household that waited less than one hour to utilize healthcare services were about 2 times higher compared to those of households that waited more than one hour to utilize healthcare services. This finding was in line with other studies where the waiting time to utilize healthcare services was associated with CBHI enrollment $[2,19,34,35]$. The shorter waiting time encourages and attracts households, which increases the interest in enrolling in $\mathrm{CBHI}$.

On the other hand, a preferred health facility during the time of sickness was a factor associated with CBHI utilization. Accordingly, the odds of CBHI utilization among those who like to get health services at the public health center and private health facilities were about 3 times higher and $60 \%$ times less compared to those who use other health facilities (public hospital and private hospital), respectively. This finding was also revealed by other studies [22, 36-38].

This might be due to the accessibility of public health centers in rural areas and the good quality of services at private health facilities.

Satisfaction with the attitude of health professionals was one of the health system-related factors associated with CBHI utilization. Accordingly, the odds of CBHI utilization among those satisfied with the attitude of health workers were $90 \%$ less compared to their counterparts. The finding was also in line with a study conducted in Nepal [39]. This was due to the unfriendly, uncompassionate, and disrespectful behavior of health workers and this might be due to lack of incentives, lack of good working environment, and job dissatisfaction.

On the other hand, the odds of CBHI utilization among households satisfied with healthcare services were about $90 \%$ less compared to their counterparts. This might be due to the availability of drugs, lack of good hospitality, and the long waiting time to utilize healthcare services. This study was also in line with other studies [30].

This study has also addressed scheme-related factors that were associated with CBHI utilization. Accordingly, the odds of CBHI utilization, affordability of premium, and registration fee of the scheme were about 3 times higher compared to those perceived unaffordable and the study was also in line with other studies [7, 28, 34, 40].

The study showed that another scheme-related factor associated with CBHI utilization was trust in the scheme management system. The odds of CBHI utilization among those who trust in the scheme were about $60 \%$ less and $70 \%$ less compared to those who partially trust in the scheme. This finding was in line with other studies [10, 41-43] and this might be due to trustworthiness which helps households to have the confidence to pay a premium.

\section{Conclusion}

The magnitude of CBHI utilization in the study area was low when compared to other previous studies and the National HSTPII target plan to achieve $80 \%$ community-based health insurance utilization. The results of the study showed that age, sex, household family size, occupational status of farmer, annual income of households, trustworthiness, affordability of the registration and premium, frequency of visit to the health facility, waiting time to get healthcare service, satisfaction with the healthcare services and the attitude of health professionals, and trustworthiness were factors significantly associated with community-based health insurance utilization. Therefore, the District Health Office and concerned officials of the program should disseminate information about $\mathrm{CBHI}$ and improve the awareness of the community. In addition, they should take measures on improving the trustworthiness of the $\mathrm{CBHI}$ management system. Health facilities should improve the quality of health services, households should encourage 
one another to join the scheme, and researchers should focus on exploring other factors associated with $\mathrm{CBHI}$ utilization.

\section{Recommendation}

(i) This study showed that the magnitude of $\mathrm{CBHI}$ utilization was low (66.3\%) compared to National HSTPII target plan of expanding CBHI schemes to $80 \%$ of districts and enrolling at least $80 \%$ of households by 2024/25.

(ii) All levels of health offices and health insurance agencies should work more to achieve a national target of CBHI utilization ( $80 \%$ ) by expanding the community-based health insurance scheme management system to the kebele level to enhance community-based health insurance utilization and improve the trustworthiness of the scheme.

(iii) Primary healthcare units should improve CBHI members' satisfaction with healthcare services, drug availability, waiting times for services, and health provider attitudes, and health workers should be compassionate and respectful. They should also continue to strengthen information and communication activities to increase community awareness so that CBHI members can benefit from the program.

(iv) Communities should participate in awareness creation, attend $\mathrm{CBHI}$ meetings, and encourage their neighbors and friends to join the scheme. All religious leaders, elders, and Abbaa Gadaas should be committed to mobilizing households to join community-based health insurance and should be involved in decision-making to increase the magnitude of CBHI utilization.

(v) Households should be aware of the scheme and feel a sense of ownership over it; they should participate in all CBHI-related meetings and decision-making and encourage one another to join the scheme and, female household heads should be encouraged to participate in the program.

(vi) Researchers should focus on factors associated with CBHI utilization and more research should be done to learn more about the factors associated with the utilization of community-based health insurance.

\section{Data Availability}

The data used to support the findings of this study are available and can be accessed from the corresponding author upon reasonable request.

\section{Additional Points}

The research attempted to assess all factors associated with community-based health insurance, but it is not exhaustive, and other factors that this study was unable to cover might exist. Some variables, such as distance from a health facility and annual income, were estimated and may not be exact. The research's other drawback is that there were insufficient comparable studies in Ethiopia as well as the study area to use as the literature review; comparison of findings was difficult. The current COVID-19 outbreak has hampered free contact with interviewees and more group debate, which may have hampered the study's inclusion of qualitative data.

\section{Conflicts of Interest}

The authors declare no conflicts of interest in this work.

\section{Authors' Contributions}

The authors significantly contributed to the work of this study and the correspondent took part in drafting revising/ reviewing it.

\section{Acknowledgments}

The authors are grateful to Adama General Hospital and the Medical College Department of Public Health for providing them with such a wonderful opportunity to pursue a General Masters of Public Health degree and write this thesis. The authors would also like to express their gratitude and deep appreciation to their advisor, Sisay Begashaw Sharo (B.S., $\mathrm{MPH}$ ), for effectively guiding and inspiring them to complete this research thesis. They are sincerely grateful to the Akaki District Administration Health Office for providing them with background information on the district's community-based health insurance utilization and for their unwavering support during the data collection and analysis.

\section{References}

[1] G. Carrin, M.-P. Waelkens, and B. Criel, "Community-based health insurance in developing countries: a study of its contribution to the performance of health financing systems," Tropical Medicine and International Health, vol. 10, no. 8, pp. 799-811, 2005.

[2] M. Mukangendo, M. Nzayirambaho, R. Hitimana, and A. Yamuragiye, "Factors contributing to low adherence to community-based health insurance in rural Nyanza district, southern Rwanda," Journal of Environmental and Public Health, vol. 2018, Article ID 2624591, 2018.

[3] P. Mladovsky and E. Mossialos, "A conceptual framework for community-based health insurance in low-income countries: social capital and economic development," World Development, vol. 36, no. 4, pp. 590-607, 2008.

[4] O. C. K. K. Hagan, P. Nsiah, D. Obiri-yeboah, F. Yirdong, I. Annan, and S. Eliason, "Vaccination with hepatitis B in Ghana: a pilot study," Journal of Public Health in Africa, vol. 9, pp. 1-4, 2018.

[5] Transitional government of Ethiopia, The national population policy of Ethiopia, 1993, https://www.phe-ethiopia.org/pdf/ Population_Policy_of_Ethiopia.pdf.

[6] B. Negash, Y. Dessie, and T. Gobena, "Community-based health insurance utilization and associated factors among informal workers in Gida Ayana District, Oromia Region," East African Journal of Health and Biomedical Sciences, vol. 3, no. 2, pp. 13-22, 2019. 
[7] S. Getachew, "Community-based health insurance and communities' scheme requirement compliance in Thehuldere district, northeast Ethiopia : cross-sectional community-based study," 2017.

[8] B. Negash, Y. Dessie, and T. Gobena, "Community based health insurance utilization and associated factors among informal workers in Gida Ayana district, Oromia region, West Ethiopia," East African Journal of Health and Biomedical Sciences, vol. 2019, no. 2, pp. 13-22, 2019.

[9] Z. Yilma, A. Mebratie, R. Sparrow, M. Dekker, G. Alemu, and A. S. Bedi, "Impact of Ethiopia's community based health insurance on household economic welfare," pp. 1-8, 2015.

[10] D. Nageso, K. Tefera, and K. Gutema, "Enrollment in community based health insurance program and the associated factors among households in Boricha district, Sidama Zone, Southern Ethiopia; a cross-sectional study," PLoS ONE, vol. 15, no. 6, pp. 1-14, 2020.

[11] World Bank, "Public Disclosure Authorized a practitioner's guide health financing," 2014, https://openknowledge. worldbank.org/bitstream/handle/10986/7094/ 370910Health0f101OFFICIAL0USE0ONLY1.pdf? sequence $=1$ \&isAllowed $=\mathrm{y}$.

[12] F. Solomon, Z. Hailu, and D. A. Tesfaye, "Ethiopia's community-based health insurance: a step on the road to universal health coverage," Health Finance and Governance, p. 12, 2011, https://www.hfgproject.org/ethiopias-community-basedhealth-insurance-step-road-universal-health-coverage/.

[13] S. Ololo and B. Megersa, "Willingness to join communitybased health insurance among rural households of Debub Bench," BMC Public Health, pp. 1-10, 2014.

[14] H. Tilahun, D. D. Atnafu, G. Asrade, A. Minyihun, and Y. M. Alemu, "Factors for healthcare utilization and effect of mutual health insurance on healthcare utilization in rural communities of South Achefer Woreda, North West, Ethiopia," Health Economics Review, vol. 8, no. 1, p. 15, 2018.

[15] G. D. Kibret, C. T. Leshargie, F. Wagnew, and A. Alebel, "Willingness to join community based health insurance and its determinants in East Gojjam zone, Northwest Ethiopia," BMC Research Notes, vol. 12, no. 1, pp. 31-35, 2019.

[16] G. Mulat Bantie, A. A. Woya, and B. M. Zewdie, "Community-based health insurance and associated Factors in NorthWestern Ethiopia. The Case of Bahir Dar city," International Journal of General Medicine, vol. 13, pp. 1207-1217, 2020.

[17] M. G. Garedew, S. O. Sinkie, D. M. Handalo et al., "Willingness to join and pay for community-based health insurance among rural households of selected districts of Jimma zone, southwest Ethiopia," Clinico Economics and Outcomes Research, vol. 12, pp. 45-55, 2020.

[18] E. Nshakira-rukundo, E. C. Mussa, N. Nshakira, N. Gerber, and J. von Braun, "Determinants of enrolment and renewing of community-based health insurance in households with under-5 children in rural south-western Uganda," International Journal of Health Policy and Management, vol. 8, no. 10, pp. 593-606, 2019.

[19] D. M. Dror, S. A. Shahed Hossain, A. Majumdar, T. L. P. Koehlmoos, D. John, and P. K. Panda, "What factors affect voluntary uptake of community-based health insurance schemes in low- and middle-income countries? A systematic review and meta-analysis," PLoS One, vol. 11, no. 8, pp. 1-31, 2016.

[20] R. Fadlallah, F. El-Jardali, N. Hemadi et al., "Barriers and facilitators to implementation, uptake and sustainability of community-based health insurance schemes in low- and middle-income countries: a systematic review," International Journal for Equity in Health, vol. 17, no. 1, pp. 13-18, 2018.

[21] A. Minyihun, M. G. Gebregziabher, and Y. A. Gelaw, "Willingness to pay for community-based health insurance and associated factors among rural households of Bugna District, Northeast Ethiopia," BMC Research Notes, vol. 12, no. 1, pp. 55-57, 2019.

[22] A. Kebede, "Willingness to pay for community based health insurance among households in the rural community of Fogera district, North west Ethiopia," International Journal of Economics, Finance and Management Sciences, vol. 2, no. 4, p. 263, 2014.

[23] A. Zergaw, Addis Ababa, Ethiopia. 2017, http://etd.aau.edu.et/ handle/123456789/12347.

[24] M. G. Abdilwohab, Z. H. Abebo, W. Godana, D. Ajema, M. Yihune, and H. Hassen, "Factors affecting enrollment status of households for community based health insurance in a resource-limited peripheral area in Southern Ethiopia. Mixed method," Plos One, vol. 16, no. 1, Article ID e0245952, 2021.

[25] P. A. Dalinjong, P. Welaga, J. Akazili et al., "The association between health insurance status and utilization of health services in rural Northern Ghana: evidence from the introduction of the National Health Insurance Scheme," Journal of Health, Population, and Nutrition, vol. 36, no. 1, pp. 42-10, 2017.

[26] E. F. Adebayo, J. E. Ataguba, O. A. Uthman, C. I. Okwundu, K. T. Lamont, and C. S. Wiysonge, "Factors that affect the uptake of community-based health insurance in low-income and middle-income countries: a systematic protocol," $B M J$ Open, vol. 4, no. 2, Article ID e004167, 2014.

[27] G. Taddesse, D. D. Atnafu, A. Ketemaw, and Y. Alemu, "Determinants of enrollment decision in the communitybased health insurance, North West Ethiopia: a case-control study," Globalization and Health, vol. 16, no. 1, pp. 4-9, 2020.

[28] T. H. Mirach, G. D. Demissie, and G. A. Biks, "Determinants of community-based health insurance implementation in west Gojjam zone, Northwest Ethiopia: a community based cross sectional study design," BMC Health Services Research, vol. 19, no. 1, pp. 544-548, 2019.

[29] E. F. Adebayo, O. A. Uthman, C. S. Wiysonge, E. A. Stern, K. T. Lamont, and J. E. Ataguba, "A systematic review of factors that affect uptake of community-based health insurance in low-income and middle-income countries," BMC Health Services Research, vol. 15, no. 1, p. 543, 2015.

[30] D. A. Adewole, S. A. Akanbi, K. O. Osungbade, and S. Bello, "Expanding health insurance scheme in the informal sector in Nigeria: awareness as a potential demand-side tool," The Pan African medical journal, vol. 27, p. 52, 2017.

[31] A. R. Sarker, M. Sultana, S. Ahmed, R. A. Mahumud, A. Morton, and J. A. M. Khan, "Clients' experience and satisfaction of utilizing healthcare services in a community based health insurance program in Bangladesh," International Journal of Environmental Research and Public Health, vol. 15, no. 8, 2018.

[32] A. D. Mebratie, R. Sparrow, and Z. Yilma, "Working Paper the impact of Ethiopia's pilot community based health insurance scheme on healthcare utilization and cost of care Degnet Abebaw," vol. 593, 2014.

[33] T. P. Koehlmoos and D. John, "Factors affecting uptake of voluntary and community-based health insurance schemes in low- and middle-income countries a systematic review June 2016 systematic," Review, vol. 27, 2016. 
[34] A. Kado, B. T. Merga, H. A. Adem, Y. Dessie, and B. Geda, "Willingness to pay for community-based health insurance scheme and associated factors among rural communities in Gemmachis district, eastern Ethiopia," ClinicoEconomics and Outcomes Research, vol. 12, pp. 609-618, 2020.

[35] E. H. Atake, "Does the type of health insurance enrollment affect provider choice, utilization and health care expenditures?" BMC Health Services Research, vol. 20, no. 1, pp. 1-14, 2020.

[36] C. L. Ranabhat and D. Acharya, "Methodological issues on challenges and opportunities towards the road of universal health coverage (UHC) in Nepal: a systematic review," Archives of Public Health, vol. 78, no. 1, pp. 1-10, 2020.

[37] S. Mulupi, D. Kirigia, and J. Chuma, "Community perceptions of health insurance and their preferred design features: implications for the design of universal health coverage reforms in Kenya," Factors affecting community based health insurance utilization, 2013, http://www.biomedcentral.com/1472-6963/ $13 / 474$.

[38] A. M. Mekonen, M. G. Gebregziabher, and A. S. Teferra, "The effect of community based health insurance on catastrophic health expenditure in Northeast Ethiopia: a cross sectional study," PLoS ONE, vol. 13, no. 10, Article ID e0205972, 2018.

[39] C. L. Ranabhat, R. Subedi, and S. Karn, "Status and determinants of enrollment and dropout of health insurance in Nepal: an explorative study," Cost Effectiveness and Resource Allocation, vol. 18, no. 1, pp. 40-13, 2020.

[40] C. A. Umeh and F. G. Feeley, "Inequitable Access to health care by the poor in community-based health insurance programs: a review of studies from low- and middle-income countries," Global Health: Science and Practice, vol. 5, no. 2, pp. 299-314, 2017.

[41] P. Schneider and F. Diop, "Synopsis of results on the impact of community-based health insurance on financial access to health care in Rwanda," Journal of Chemical Information and Modeling, vol. 53, pp. 1689-1699, 2001.

[42] E. M. Bayked, M. H. Kahissay, and B. D. Workneh, "Factors affecting community based health insurance utilization in Ethiopia: a systematic review," pp. 1-31, 2019.

[43] A. S. Badacho, K. Tushune, Y. Ejigu, and T. M. Berheto, "Household satisfaction with a community-based health insurance scheme in Ethiopia," BMC Research Notes, vol. 9, no. 1, p. 424, 2016. 